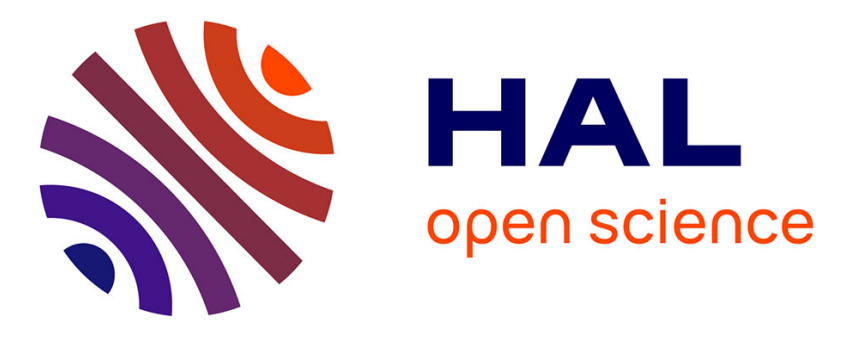

\title{
Workload and non-contact injury incidence in elite football players competing in European leagues.
}

\author{
Barthelemy Delecroix, Benoit Delaval, Brian Dawson, Serge Berthoin,
} Gregory Dupont

\section{To cite this version:}

Barthelemy Delecroix, Benoit Delaval, Brian Dawson, Serge Berthoin, Gregory Dupont. Workload and non-contact injury incidence in elite football players competing in European leagues.. European Journal of Sport Science, 2018, European journal of sport science, pp.1-8. 10.1080/17461391.2018.1477994 . hal-02378973

HAL Id: hal-02378973

https://hal.univ-lille.fr/hal-02378973

Submitted on 25 Nov 2019

HAL is a multi-disciplinary open access archive for the deposit and dissemination of scientific research documents, whether they are published or not. The documents may come from teaching and research institutions in France or abroad, or from public or private research centers.
L'archive ouverte pluridisciplinaire HAL, est destinée au dépôt et à la diffusion de documents scientifiques de niveau recherche, publiés ou non, émanant des établissements d'enseignement et de recherche français ou étrangers, des laboratoires publics ou privés. 


\title{
Title: Workload and injury incidence in elite football academy players.
}

\author{
Barthélémy Delecroix ${ }^{1,2}$, Benoit Delaval ${ }^{2,3}$, Brian Dawson ${ }^{4}$, Serge
}

Berthoin $^{1}$, Gregory Dupont ${ }^{5}$

${ }^{1}$ Univ. Lille, Univ. Artois, Univ. Littoral Côte d'Opale, EA 7369 - URePSSS - Unité de Recherche Pluridisciplinaire Sport Santé Société, F-59000 Lille, France.

${ }^{2}$ LOSC Lille Métropole

${ }^{3}$ Université de Picardie Jules Verne, EA 3300 - APERE - Adaptations physiologiques à l'exercice et réadaptation à l'effort, Amiens, France.

${ }^{4}$ School of Human Sciences (Sport Science, Exercise and Health), The University of Western Australia, Perth, Australia.

${ }^{5}$ The Football Exchange, Research Institute for Sport and Exercise Sciences, Liverpool John Moores University, Liverpool UK.

Corresponding author:

Gregory Dupont. The Football Exchange, Research Institute for Sport and Exercise Sciences, Liverpool John Moores University, Liverpool UK. email address:

G.Dupont@ljmu.ac.uk 
1 Workload and injury incidence in elite football academy players.

2

3

4

5

6

7

8

9

10

11

12

13

14

15

16

17

18

19

20

21

22

23

24

Abstract

The aim of this study was to prospectively analyse the relationship between workloads and injury in elite football academy players.

Elite football academy players $(\mathrm{n}=122)$ from under-19 (U19) and under-21

(U21) of a professional football team competing in UEFA European Cups were

followed during 5 seasons. Injuries were collected and absolute workload and

workload ratios (4-weeks, 3-weeks, 2-weeks and week-to-week) calculated using

a rolling days method with the help of the session Rate of Perceived Exertion.

There was no association between absolute workload or workload ratio with the injury incidence in the U19. In the U21, the level of cumulative absolute workloads during 3-weeks $(R R=1.39, p=0.026)$ and during 4-weeks $(R R=1.40$, $\mathrm{p}=0.019$ ) were associated with an increase in injury. There was no association between workload ratio and injury in $\mathrm{U} 21$.

The significant link between high cumulated 3 -weeks and 4 weeks workloads and injury in $\mathrm{U} 21$ confirmed the requirement to monitor the internal subjective workload in U21 in order to prevent injury. Further studies exploring the relationships between workload and injury are required in football academy.

Keywords: Training, Academy, Team Sport, Injury prevention. 
26 Mean injury incidence (match and training) across seven UEFA clubs during seven

27 seasons was reported as eight injuries per 1,000 hours of exposure, which corresponds to 50 injuries per season in a team of 25 players, or two injuries per player per season (Ekstrand, Hagglund, \& Walden, 2011). This injury incidence is 1,000 times higher than

30 in typical industrial occupations considered as highly risked (Drawer and Fuller, 2002).

31 During the 2012 Olympics, the football competition represented the highest level of injury, with $35.2 \%$ of total number of injuries during the Olympics (Engebretsen et al., 2013). This high injury incidence highlights the importance of injury prevention in elite 34 football. injuries, once the injury incidence and severity have been evaluated through epidemiological studies, the second step to prevent injury risk is to identify the risk factors and injury mechanisms. The third step is to introduce measures that are likely to

40 reduce the future risk and/or severity of injuries. The last step is characterised by

41 assessing the effect of the measures by repeating the first step (Van Mechelen, Hlobil,

$42 \&$ Kemper, 1992). According to this model, several injury risk factors have been

43 identified. In a survey, McCall et al. (2014a) reported that elite football

44 medicine/science practitioners considered previous injury as the most important injury

45 risk factor (121 points of importance on a score of 132). In their systematic review,

46 McCall et al. (2014b) confirmed the practitioners' perceptions: previous injury was the

47 injury risk factor with the highest level of scientific evidence (level 2++ according to

48 the system for graded recommendations guidelines published in British Medical

49 Journal) (Harbour and Miller, 2001). A previous hamstring, calf, groin or knee injury 
50 increases two to three times the risk to sustain a new injury in the same body part during

51 the following season (Hagglund et al., 2013). A previous injury also increases the overall injury risk, and not only in the previously injured body part (hazard ratio $=2.7$, CI95\% 1.7 to 4.3) (Hagglund et al., 2006). As a previous injury is a non-modifiable internal injury risk factor, it is important to prevent initial injuries which occur during the youth academy period. The fact to have already been injured during this period would become a non-modifiable risk factor in their future professional career.

Moreover, during an injury period, youth players do not have the same training protocol, it could represent an additional gap to bridge in their improvements. Several studies examined the injury incidence in elite youth football academy. In a systematic review of literature, Pfirrmann et al. (2016) reported, in youth academies, an overall injury incidence from 2.0 to 19.4 injuries per $1,000 \mathrm{~h}$ of exposition and a training injury incidence in youth academies from 3.7 to 11.4 injuries per $1,000 \mathrm{~h}$ of training. For the last year spent in the academy, the overall injury incidence of U18 and U19 (between 6.8 and 10 per 1,000h of exposition) (Nilsson et al., 2016 ; Renshaw \& Goodwin, 2016) is comparable to the one reported in elite professional football players (7.6 injuries per 1,000h of exposition) (Ekstrand, Hagglund, Kristenson, Magnusson \& Walden, 2013). These results concerning the high injury incidence in youth football academy highlights the needs to identify injury risk factors with this population in order to implement injury prevention strategies, especially to reduce the risk to sustain a first injury. Although a few studies have already dealt on the identification of the risk factors and injury prevention in youth academy (Bowen et al., 2017), most of the studies dealt on highlevel professional players (Ekstrand, Hagglund, \& Walden, 2011; Hagglund, Walden, \& Ekstrand, 2013). 
In their survey, McCall et al. (2014a) reported that the practitioners considered

75 the fatigue (105 points of importance on a maximal score of 132) as the second most

76 important injury risk with professional football players. Fatigue could come from the

77 repetition of training and matches. Several studies found a significant association

between workload and injury incidence among professional football players (Malone et al., 2017; Lu et al., 2017 ; Jaspers et al., 2017). Two reviews of literature concluded that internal/subjective tools were more sensitive and related to injury incidence than external and/or objective tools (Saw, Main, \& Gastin, 2016; Jones, Griffiths, \& Mellalieu, 2017). Jones, Griffiths, \& Mellalieu (2017) included 21 studies evaluating the association between internal workload and injury incidence in sports in a systematic authors concluded that there was a moderate evidence that the internal workload was associated with injury incidence. In professional football, Malone et al. (2017) identified that an absolute workload calculated with sRPE higher than 1,500 arbitrary units (A.U.) was associated with an elevated injury risk, and that an acute:chronic workload ratio calculated with the sRPE between 1.00 and 1.25 was associated with a 90 lower injury incidence in elite football players. In youth elite football players, one study

91 identified an association between the one week absolute workload calculated using the session Rate of Perceived Exertion (sRPE), using a modified perception scale (Borg,

93 CR-10) and the injury incidence (OR=1.01, 95\%CI 1.00 to 1.06) (Brink et al., 2010).

94 However, in this study, the workload was calculated only for 1 week, while associations

95 between external workload and injury incidence during 2, 3 or 4 cumulative weeks and

96 A:C ratios have been identified (Bowen et al., 2017). To our knowledge, no study aimed

97 at evaluating the association of absolute internal workload during several weeks, and acute:chronic internal workload ratio and injury in a elite football academy. Therefore, 
99 the aim of this study is to analyse the relationships between several combinations of

100 internal workload using the sRPE and the injury among football players in an elite

101 football academy.

102

$103 \quad$ Materials and Methods

$104 \quad$ Subjects

105 One hundred twenty-two elite young football players (height: $178.6 \pm 6.8 \mathrm{~cm}$; body

106 mass: $70.9 \pm 7.3 \mathrm{~kg})$ from $\mathrm{U} 19(\mathrm{n}=52$; age: $16.8 \pm 0.9)$ and $\mathrm{U} 21(\mathrm{n}=70$; age: $20.1 \pm 0.3)$

107 squads of a football academy in an elite football club playing in first French League and

108 taking part regularly in European competitions were followed during four and five

109 seasons respectively. All players from the U19 and the U21 squads were included in the

110 study. The players lived in the academy. If a player joined the team during the

111 observational period, he was included from the date he joined the team. A player who

112 left the team during the observational period was excluded from the study from the date

113 he left the team. If a player was already injured at the start of data collection, he was

114 included in the study but this injury was excluded (Fuller et al., 2006). All players were

115 informed and consented to take part in the study. This study was conducted in

116 accordance with the local ethical committee on biomedical research (CCTIRS\#10544)

117 and the standards of the declaration of Helsinki.

118

119

Methodology

120 This study was a prospective cohort study. An injury was defined, in accordance with

121 the FIFA consensus, as any physical complaint sustained by a player that resulted from

122 a football match or football training, that made the player unable to participate in future

123 football training or a match (Fuller et al., 2006). 
The workload was calculated by the sRPE method. This method is valid

126 for its use with athletes and football players (Foster, 1998 ; Impellizzeri et al., 2004).

127 Players were instructed to rate the global intensity of all sessions and matches using a

128 modified category ratio scale going from 0 to 10 based on the scale developed by Borg

129 (1987) by answering the following question: 'How was your workout?'. The sRPE was

130 collected 30 minutes after completion of the session/match by a sport clinician working

131 in the club responsible for the collection of the data. The players were isolated to

132 answer in order not to be influenced by other players. Workload, expressed in arbitrary

133 units (AU) was calculated by multiplying the perceived intensity by the session or

134 match duration (Foster et al., 2001); all training sessions and all matches were included.

135 All the training sessions and matches were on natural grass. The workload was

136 calculated on a daily basis with the methods of rolling days blocks (everyday, a new

137 workload was calculated based on the preceding days) (Hulin et al., 2016; Bowen et al.,

138 2017). The absolute workload was the sum of the load for the last 7 days (one-week

139 workload), 14 days (2-weeks workload), 21 days (3-weeks workload) and 28 days (4-

140 weeks workload) were calculated. To determine A:C ratios, the one-week workload was

141 divided by the total workload of the last 28 days, divided by 4 for the 4 -weeks A:C ratio

142 (formula: one-week workload / (last 28 days workload/4)), the total load of the last 21

143 days divided by 3 for the 3-weeks A:C ratio (one-week workload / (last 21 days

144 workload/3)) and the total load of the last 14 days divided by 2 for the 2 weeks A:C

145 ratio (one-week workload / (last 14 days workload/2)) (Malone et al., 2017). The week-

146 to-week load changes were also calculated by dividing the 1-week load by the

147 accumulated load of the previous 7 days. The workload was known by the practitioners

148 who could use the data to regulate the workload. In U19, the group (and not individual) 
149 workload was regulated on a weekly basis by the practitioners. The workload was

150 analysed in the end of each week and the practitioners aim was to reach a weekly mean

151 of 2,500 A.U, because they considered it was the optimal workload to reduce the injury

152 risk while improving players fitness qualities. The data were not taken into account in

153 U21 to regulate the workload.

154

155

Statistical Analysis

156 A Poisson regression analysis was performed with IBM SPSS Statistics Version 20 for

157 the 1-week, 2-weeks, 3-weeks and 4-weeks absolute workload and the A:C workload

158 ratios to assess the link between these factors and injury incidence and calculate relative

159 risk (RR). The absolute workload and the A:C workload ratios were log-transformed

160 when the scores were not normally distributed.

161 The daily probability to sustain an injury was calculated by dividing the number of

162 injuries by the number of days of observation, multiplied by 100.

163

164

\section{Results}

165 A total of 122 players have been followed during the period of observation. The number

166 of players in each squad, season by season, are described in table 1 . In U19 category, a

167 total 52 players were followed (24 players were followed during one season, 26 players

168 were followed during two seasons, 2 players were followed during 3 seasons). In U21

169 category, a total of 70 players were followed (41 players were followed during one

170 season, 16 players were followed during 2 seasons, 8 players were followed during 3

171 seasons, 4 players were followed during 4 seasons and one player was followed during

172 the 5 seasons of observation). It represents a total of 200 player-seasons, 17,778 days in

173 the U19 and of 26,672 days in the U21 were recorded. 
175 A total of 182 injuries were recorded in the U19 category (119 non-contact +63

176 contact injuries) and of 307 injuries (215 non-contact + 92 contact injuries) were

177 recorded in the U21 category. It represents a global injury incidence of 7.6 injuries per

$1781,000 \mathrm{~h}$ of exposition for the U19 and of 9.6 injuries per 1,000h of exposition for the

$179 \mathrm{U} 21$. The daily probability to sustain an injury was $1.02 \%$ in U19 and $1.15 \%$ in U21.

180 In U19, the mean weekly workload was $2046 \pm 705 \mathrm{AU}$; the mean 2 weeks

workload was $3813 \pm 1291 \mathrm{AU}$; the mean 3 weeks workload was $5501 \pm 1831 \mathrm{AU}$ and the

mean 4 weeks absolute workload was $7104 \pm 2334$ AU. No link was found between

absolute workload, cumulative absolute workload (2 weeks, 3 weeks, 4 weeks) and

184 global, non-contact or contact injuries with U19 players. These results are described in

185 table 2. No link was found between none of the A:C workload ratio and global, non-

mean 4 weeks workload was $7145 \pm 2254 \mathrm{AU}$. The results concerning the link between absolute workload and global, non-contact and contact injuries in U21 are described in table 4. An association was found between the cumulative 3 weeks absolute workload and injury incidence $(\mathrm{R} R=1.39, \mathrm{p}=0.026)$ and between the cumulative 4 weeks absolute

197 the A:C workload ratio and the injury incidence with $\mathrm{U} 21$ players. The results are

198 described in table 5. 


\section{Discussion}

204 The aim of this study was to analyse the relationship between workload and injury

205 incidence in elite football academy players. The main findings showed that there was no

206 association between absolute or A:C workload ratio with U19 players, while there was

207 an association between 3 weeks and 4 weeks cumulative absolute workload with U21

208 players.

209

In the current study, the overall injury incidence was 7.6 injuries per $1,000 \mathrm{~h}$ of

211 exposition with U19 and 9.6 injuries per 1,000h of exposition with U21 players. These

212 results confirm those of previous studies with an overall injury incidence between 6 and

21310 injuries per 1,000h of exposition with players in U18 and U19 categories (Nilsson et

214 al., 2016; Renshaw \& Goodwin, 2016). This injury incidence is also close to the injury

215 incidence of elite professional football teams ( 8 injuries per $1,000 \mathrm{~h}$ of exposition)

216 (Ekstrand, Hagglund, \& Walden, 2011). When transforming these results into daily

217 probability, the overall daily probability to sustain an injury in U19 is $1.02 \%$ per player

218 and in U21 is $1.15 \%$ per player. The daily probability to sustain an injury per player

219 highlights that even if the injury incidence is very high compared to other activities

220 (Ekstrand, 2013), the daily probability to sustain an injury in a youth academy is low,

221 being approximately $1 \%$. 
No link between absolute workload, A:C workload ratio and injury incidence

224 was found for the U19. These results about the lack of significant relationship between

225 absolute workload and the occurrence of injury are different of a previous study led by

226 Brink et al. (2010), who found an association between internal workload calculated

227 using the sRPE and the injury incidence. However, the methodology used are different.

228 First of all, Brink et al. analysed the sum of the workload week after week, while in the

229 current study, a rolling days method was used to analyse the workload day after day.

230 This is a major difference between the two studies as an injury at the beginning of the

231 week or in the end of the week could lead to big changes in the weekly workload with

232 Brink et al.'s methodology (2010). In the study led by Brink et al. (2010), an odd ratio

233 was calculated, while in the current study, a Poisson regression was used, providing a

234 relative risk. The injury incidence in Brink et al. study (2010) (37.55 per 1,000h of

235 match and 11.14 per $1,000 \mathrm{~h}$ of training) was higher than the one in the present study

236 (7.6 in $\mathrm{U} 19$ and 9.6 in $\mathrm{U} 21$ ). The probability to find a significant association between a

237 potential risk factor and an event depends on the event frequency. It means that the

238 higher the injury incidence is, the higher the probability to find a significant statistical

239 association is (Bahr and Holme, 2003). The method to calculate the workload was not

240 exactly the same as the authors used a 15-point scale to rate the perceived intensity and

241 multiply the perceived exertion by the number of hours of practice while a 10-point

242 scale was used in the present study and the exertion was multiplied by the number of

243 minutes of practice. It is therefore difficult to compare the workload data range width

244 while the data range width of the independent factor modifies the results of a regression

245 (Salgueiro da Silva and Seixas, 2017). Another difference in the results could be

246 explained by a different definition of injury, as Brinks et al. (2010), defined the injury

247 as any physical complaint sustained by a player that results from a soccer match or 
248 soccer training and leading to time loss or medical attention. In the present study, only

249 the complaint leading to time loss were taken into account. Given the very low odd ratio $250(\mathrm{OR}=1.01,95 \% \mathrm{CI} 1.00$ to 1.02$)$ reported by Brink et al. (2010), these changes in the

251 methodology could explain the absence of association in the current study and the

252 differences between the two studies.

253

254

In the $\mathrm{U} 21$, no association was found between none of the A:C workload while

an association was found between the cumulative absolute 3 weeks and 4 weeks

workload and the injury incidence. In the current study, no association has been found

with none of the workload calculated over the last 7 days (absolute 1 week workload or

258 A:C workload ratio). These results does not allow to identify a link between the internal

259 A:C workload ratios calculated with sRPE and injury incidence with academy players

260 while this association has been identified with professional players (Malone et al.,

261 2017). In professional football, an A:C ratio between 1.00 and 1.25 has been identified

262 as an injury protective factor (Malone et al., 2017). An elevated A:C workload ratio is

263 the result of the combination of a low chronic workload and a high acute workload

264 (Blanch \& Gabbett, 2016). It means that a low chronic workload or spikes in the

265 workload calculated with sRPE should be avoided in elite level football players in

266 order to reduce the injury incidence (Blanch \& Gabbett, 2016). Jaspers et al. (2018)

267 identified that an elevated workload calculated with the help of sRPE during two weeks

268 was associated with an elevated incidence of overuse injury with elite football players

269 while a medium workload during four weeks was associated with a decrease in injury

270 incidence in comparison with a low workload calculated with sRPE. This result

271 indicates that a minimum level workload should be necessary to avoid an increase in

272 injury risk, and that a chronic workload too low could be an injury risk factor among 
273 professional football players. These results highlight the association between injury

274 incidence and acute and chronic workload calculated with sRPE in professional

275 football. This association has not been found in the present study with academy players.

276 Differences between players playing in a youth football academy and professional

277 football players playing in European competitions could be explained by differences in

278 the changes in acute workload. Large changes in workload sustained by professional

279 football players could occur during the congested schedule with two to three-games per

280 week. The schedule in youth category seems to be more regular without congested

281 periods, leading to smaller changes in the acute workload. These differences in the

282 competitions schedules could explain the absence of association between A:C workload

283 ratio and injury incidence in the U19 and U21 age categories.

284

285

The difference in results between U19 and U21 in the present study could be

286 explained in part by the smaller number of injuries recorded in U19 compared to U21

287 (182 vs 307), which is explained by a lower incidence (7.6 vs 9.6) and shorter period of

288 observation in U19 in comparison with the U21 (4 seasons vs 5 seasons). There was a

289 similar proportion of non-contact injuries between U19 and U21 (65\% in U19 vs 71\%

290 in U21), but a lower number of non-contact injuries recorded in U19 (119 vs 215),

291 which also could explain the absence of association in U19 as non-contact injuries are

292 considered easier to prevent than contact injuries (Gabbett et al., 2010). As explained in

293 the introduction, a previous injury is the strongest injury risk factor. In future studies, it

294 may be interesting to evaluate the effect of a previous injury on the ability of a player to

295 sustain high workload, as the present results indicate that older players (U21) are more

296 sensitive to high workload, which may be linked to a higher proportion of previously

297 injured players with older players. 
This study presents some limitations. First of all, the current study identified an

300 association between absolute workload and injury incidence with players in a football

301 academy but it does not necessarily mean that there is a causal connection between

302 workload and injury incidence (Bahr, 2016). Although very complicated to implement

303 in the real high-level sport world, other studies and randomised controlled trials should

304 be assessed to analyse the effect of a controlled workload on the injury incidence, in an

305 isolated way, to confirm a causal connection (Bahr, 2016). As a cohort study, the design

306 represents a limit. The observation of the players means that the results are influenced

307 by players sustaining several injuries and as such are considered as repeated

308 independent observations while these injuries are multifactorial and are linked to a lot of

309 factors dependent of the player observed, as, for example, the ability to cope with very

310 high load and/or to large variations in workload. One of the limits of this study is the

311 low injury incidence in this study with only 182 injuries for 17,778 days of observation

312 in U19 and 372 injuries for 26,672 days of observation in U21, representing a daily

313 probability to sustain an injury of $1.02 \%$ in U19 and of $1.15 \%$ in U21. This low

314 probability could explain in part the absence of statistical association in U19 as a low

315 occurrence of an event reduces the probability to find an association between this event

316 and an independent factor (Bahr and Holme, 2003). Another limit of the study concerns

317 the practitioners who recorded the data. If they adapted the workload according to the

318 data recorded to protect some players with very high of low workloads, it would impact

319 the results. This limit could also partly explain the absence of results in U19 compared

320 to the results in U21. In U19, the workload was regulated on a weekly basis by the

321 practitioners. The objective for the practitioners in U19 was to reach a mean weekly

322 group workload of 2,500 A.U., and was analysed in the end of each week to decide how 
323 to manage the group workload in the following week. It could explain why the

324 workload is not associated with the injury incidence in U19. In U21, the data were

325 known by the practitioners but not used to regulate the workload, which could partly

326 explain the differences in the results between the two categories.

Despite these limits, this study presents some interesting strengths. First of all,

329 to our knowledge, this is the first study with elite football academy players analyzing

330 the associations of multiple combinations of internal absolute workload and workload

331 ratios with injury incidence.

With 122 players followed and 200 player-seasons, the cohort of this study was

334 large compared to other studies in the same topic. It is, to our knowledge, the first

335 longitudinal study concerning young football players led during a period as long as five

336 full seasons. The players followed were football players from an elite football academy.

337 It means that there was a very good control about the workload with no missing data

338 and a very good control of the outside activities of the players as most of the players

339 were staying in the academy. It gives a very high level of confidence to the recorded

340 workload.

\section{Conclusion}

343 In conclusion, the results of this study indicated that the internal workload calculated

344 using the sRPE was not associated with injury incidence in U19. In the U21 category,

345 the absolute workload cumulated during 21 or 28 days is positively associated with the

346 injury incidence. This result indicates that practitioners working with young football

347 players could calculate the internal workload and use the sRPE during their late years of 
348 academy in order to potentially reduce the injury incidence. Further studies are required

349 in these age categories to analyse these associations.

350

\section{Acknowledgements}

352 The authors thank all the players who took part in the study.

353

354

\section{Declaration of interest statement}

The authors report no conflict of interest.

356

357

Akenhead, R., \& Nassis, G. P. (2016). Training load and player monitoring in high-

360 level football: current practice and perceptions. International Journal of Sports

361

362

Bahr R., \& Holme I. (2003). Risk factors for sports injuries - a methodological approach. British Journal of Sports Medicine, 37, 384-392. Physiology and Performance, 11, 587-793.

Bahr, R. (2016). Why screening tests to predict injury do not work and probably never will...: a critical review. British Journal of Sports Medicine, 50, 776-780.

Blanch, P., \& Gabbett, T. J. (2016). Has the athlete trained enough to return to play safely? The acute:chronic workload ratio permits clinicians to quantify a player's risk of subsequent injury. British Journal of Sports Medicine, 50, 471475. rate and blood lactate during arm and leg exercise. European Journal of Applied Physiology and Occupational Physiology, 56, 670-685. 
377 Bowen, L., Gross, A. S., Gimpel, M., \& Li, F. X. (2017). Accumulated workloads and

378

379

380

381

382

383

384

385

386

387

388

389

390

391

392

393

394

395

396

397

398

399

400

401

402

403

404

405

406

407

408

409

410 the acute:chronic workload ratio relate to injury risk in elite youth football players. British Journal of Sports Medicine, 51, 452-459.

Brink, M. S., Visscher, C., Arends, S., Zwerver J., Post W. J., \& Lemmink K. A. P. M. (2010). Monitoring stress and recovery: new insights for the prevention of injuries and illnesses in elite youth soccer players. British Journal of Sports Medicine, 44, 809-815.

Carey, D. L., Blanch, P., Ong, K. L., Crossley, K. M., Crow, J., \& Morris, M. E. (2016). Training loads and injury risk in Australian football-differing acute:chronic workload ratios influence match injury risk. British Journal of Sports Medicine, $51,1215-1220$

Ekstrand J., Hagglund M., \& Walden M. (2011). Epidemiology of muscle injuries in professional football (soccer). American Journal of Sports Medicine, 39, 12261232.

Ekstrand, J., Hagglund, M., \& Walden, M. (2011). Injury incidence and injury patterns in professional football: the UEFA injury study. British Journal of Sports Medicine, 45, 553-558.

Ekstrand, J. (2013). Keeping your top players on the pitch: the key to football medicine at the professional level. British Journal of Sports Medicine, 47, 723-724.

Foster, C. (1998). Monitoring training in athletes with reference to overtraining syndrome. Medicine \& Science in Sports \& Exercise, 30, 1164-1168.

Foster, C., Florhaud, J. A., Franklin, J., Gottschall, L., Hrovantin, L. A., Parker, S., Doleshal, P., \& Dodge, C. (2001). A new approach to monitoring exercise training. Journal of Strength and Conditioning Research, 15, 109-115.

Fuller, C. W., Ekstrand, J., Junge, A., Andersen, T. E., Bahr, R., Dvorak, J., Hägglund, M., McCrory, P., \& Meeuwisse, W. H. (2006). Consensus statement on injury 
British Journal of Sports Medicine, 40, 193-201.

Gabbett, T. J. (2010). The development and application of an injury prediction model for noncontact, soft-tissue injury in elite collision sport athletes. Journal of Strength and Conditioning Research, 24, 2593-2603.

Hagglund, M., Walden, M., \& Ekstrand, J. (2006). Previous injury as a risk factor for injury in elite football: a prospective study over two consecutive seasons. British Journal of Sports Medicine, 40, 767-772.

Hagglund, M., Walden, M., \& Ekstrand, J. (2013). Risk factors for lower extremity muscle injury in professional soccer. American Journal of Sports Medicine, 41, 327-335.

Harbour, R., \& Miller, J. (2001). A new system for grading recommendations in evidence based guidelines. British Medical Journal, 323, 334-336.

Hulin, B. T., Gabbett, T. J., Lawson D. W., Caputi P., \& Sampson J. A. (2016). The acute:chronic workload ratio predicts injury: high chronic workload may decrease injury risk in elite rugby players. British Journal of Sports Medicine, 50, 231-236.

Impellizzeri, F. M., Rampinini, E., Coutts, A. J., Sassi, A., \& Marcora, S. M. (2004). Use of RPE-based training load in soccer. Medicine \& Science in Sports \& Exercise, 36, 1042-1047.

Jaspers, A., Brink M. S., Probst, S. G., Frenken W. G., \& Helsen W. F. (2017). Relationships between training load indicators and training outcomes in professional soccer. Sports Medicine, 47, 533-544.

Jaspers, A., Kuyvenhoven, J. P., Staes, F., Frencken, W. G. P., Helsen, W. F., \& Brink, M. S. (2018). Examination of the external and internal load indicators 
Jones, C. M., Griffiths, P. C., \& Mellalieu, S. D. (2017). Training load and fatigue marker associations with injury and illness: A systematic review of longitudinal studies. Sports Medicine, 47, 943-974.

Lu, D., Howle, K., Waterson, A., Duncan, C., \& Duffield, R. (2017). Workload profiles prior to injury in professional soccer players. Science and Medicine in Football, 3, 237-243.

Malone, S., Owen, A., Newton, M., Mendes, B., Collins, K. D., \& Gabbett, T. J. (2017). The acute:chronic workload ratio in relation to injury risk in professional soccer. Journal of Science and Medicine in Sport, 20, 561-565.

McCall, A., Carling, C., Nedelec, M., Davison, M., Le Gall, F., Berthoin, S., \& Dupont, G. (2014a). Risk factors, testing and preventative strategies for non-contact injuries in professional football: current perceptions and practices of 44 teams from various premier leagues. British Journal of Sports Medicine, 49, 583-589.

McCall, A., Carling, C., Michael, D., Nedelec, M., Le Gall, F., Berthoin, S., \& Dupont, G. (2014b). Injury risk factors, screening tests and preventative strategies: a systematic review of the evidence that underpins the perceptions and practices of 44 football (soccer) teams from various premier leagues. British Journal of Sports Medicine, 49, 583-589.

Nilsson, T., Ostenberg, A. H., \& Alricsson, M. (2016). Injury profile among elite male youth soccer players in a Swedish first league. Journal of Exercise Rehabillitation, 12, 83-89.

Pfirrmann, D., Herbst, M., Ingelfinger, P., Perikles, S., \& Tug, S. (2016). Analysis of injury incidences in male professional adult and elite youth soccer players: A systematic review. Journal of Athletic Training, 51, 410-424. 
478 Renshaw, A., \& Goodwin P. C. (2016). Injury incidence in a Premier League youth soccer academy using the consensus statement: a prospective cohort study. British Medicine Journal Open Sport and Exercise Medicine, 2, e000132.

481

482 Salgueiro da Silva, M. A., \& Seixas, T. M. (2017). The role of data range in linear 483 regression. The Physics Teacher, 55, 371-372.

484

485 Saw, A. E., Main, L. C., \& Gastin, P. B. (2016). Monitoring the athlete training 486 response: subjective self-reported measures trump commonly used objective measures: a systematic review. British Journal of Sports Medicine, 50, 281-291.

488

van Mechelen, M., Hlobil, H., \& Kemper, H. C. (1992). Incidence, severity, aetiology 490 491 and prevention of sports injuries. A review of concepts. Sports Medicine, 14, 8289.

492

493 Walden M., Hagglund M., \& Ekstrand J. (2005) UEFA Champions League study: a 494 prospective study on injuries in professional football during the 2001-2002 season. British Journal of Sports Medicine, 39, 542-546.

496

497 
498 Table 1: Number of players observed in U19 and U21 during the 5 seasons of 499 observation.

\begin{tabular}{lcc}
\hline & $\begin{array}{c}\text { Number of players observed } \\
\text { in U19 }\end{array}$ & $\begin{array}{c}\text { Number of players observed } \\
\text { in U21 }\end{array}$ \\
\hline $\mathbf{2 0 1 2 - 2 0 1 3}$ & $\mathrm{X}$ & 21 \\
$\mathbf{2 0 1 3 - 2 0 1 4}$ & 18 & 26 \\
$\mathbf{2 0 1 4 - 2 0 1 5}$ & 16 & 24 \\
$\mathbf{2 0 1 5 - 2 0 1 6}$ & 23 & 28 \\
$\mathbf{2 0 1 6 - 2 0 1 7}$ & 25 & 19 \\
\hline
\end{tabular}

500

501 Table 2: Relative risk RR (95\% confidence interval) and p-value for an increase in

502 cumulative workload for the last 7 days (1 week), 14 days (2 weeks), 21 days (3 weeks)

503 and 28 days (4weeks) in the U19 age category.

\begin{tabular}{lcc}
\hline & $\begin{array}{c}\text { RR } \\
(\mathbf{9 5 \%} \mathbf{C I})\end{array}$ & $\mathbf{p}$ \\
\hline 1 week workload & 1.11 & 0.44 \\
\hline 2 weeks cumulative workload & $(0.84-1.50)$ & 0.85 \\
& 1.03 & 0.82 \\
$\mathbf{3}$ weeks cumulative workload & $(0.77-1.38)$ & 0.97 \\
\hline 4 weeks cumulative workload & $(0.74-1.28)$ & \\
\hline
\end{tabular}

504

505 Table 3: Relative risk RR (95\% confidence interval) and p-value for an increase in

506 Acute:Chronic workload with a chronic workload calculated over the last the last 28

507 days (4weeks), the last 21 days (3 weeks), the last 14 days (2 weeks) and the week to

508 week changes in workload in the U19 age category.

\begin{tabular}{lcc}
\hline & $\begin{array}{c}\text { RR } \\
(\mathbf{9 5 \%} \mathbf{C I})\end{array}$ & $\mathbf{p}$ \\
\hline 4 weeks A:C workload & 1.01 & 0.73 \\
3 weeks A:C workload & $(0.96-1.07)$ & 0.91 \\
2 weeks A:C workload & 1.00 & 0.82 \\
$(0.95-1.06)$ & 0.99 \\
$\begin{array}{l}\text { Week to week workload } \\
\text { changes }\end{array}$ & $(0.90-1.09)$ & 0.93 \\
\hline
\end{tabular}


510 Table 4: Relative risk RR (95\% confidence interval) and p-value for an increase in 511 cumulative workload for the last 7 days (1 week), 14 days (2 weeks), 21 days (3 weeks)

512 and 28 days (4weeks) in the U21 age category.

\begin{tabular}{lcc}
\hline & $\begin{array}{c}\mathbf{R R} \\
(\mathbf{9 5 \%} \mathbf{C I})\end{array}$ & $\mathbf{p}$ \\
\hline $\mathbf{1}$ week workload & 1.18 & 0.19 \\
$\mathbf{2}$ weeks cumulative workload & $(0.92$ to 1.52$)$ & 0.076 \\
$\mathbf{3}$ weeks cumulative workload & 1.28 & 0.026 \\
$\mathbf{4}$ weeks cumulative workload & $(0.97$ to 1.69$)$ & 0.019 \\
& $(1.04$ to 1.84$)$ & \\
\hline
\end{tabular}

513

514 Table 5: Relative risk RR (95\% confidence interval) and p-value for an increase in

515 Acute:Chronic workload with a chronic workload calculated over the last the last 28

516 days (4weeks), the last 21 days (3 weeks), the last 14 days (2 weeks) and the week to

517 week changes in workload in the $\mathrm{U} 21$ age category.

\begin{tabular}{lcc}
\hline & $\begin{array}{c}\mathbf{R R} \\
(\mathbf{9 5 \%} \mathbf{C I})\end{array}$ & $\mathbf{p}$ \\
\hline $\mathbf{4}$ weeks A:C workload & 0.89 & 0.34 \\
$\mathbf{3}$ weeks A:C workload & $(0.71$ to 1.13$)$ & 0.37 \\
$\mathbf{2}$ weeks A:C workload & 0.88 & 0.47 \\
& $(9.66$ to 1.16$)$ & 0.91 \\
\hline $\begin{array}{l}\text { Week to week workload } \\
\text { changes }\end{array}$ & $\begin{array}{l}0.86 \\
(0.58 \text { to } 1.29)\end{array}$ & \\
\hline
\end{tabular}

518 
Title: Workload and injury incidence in elite football academy players.

Title: Workload and injury incidence in elite football academy players. 


\section{Workload and injury incidence in elite youth football players.}

2

3

4

5

6

7

8

9

10

11

12

13

14

15

16

17

18

19

20

21

22

23

24

Abstract

The aim of this study was to prospectively analyse the relationship between workloads and injury in elite football academy players.

Elite football academy players $(\mathrm{n}=122)$ from under-19 (U19) and under-21 (U21) of a professional football team competing in UEFA European Cups were followed during 5 seasons. Injuries were collected and absolute workload and workload ratios (4-weeks, 3-weeks, 2-weeks and week-to-week) calculated using a rolling days method with the help of the session Rate of Perceived Exertion.

There was no association between absolute workload or workload ratio with the injury incidence in the U19. In the U21, the level of cumulative absolute workloads during 3-weeks ( $R R=1.39, p=0.026)$ and during 4-weeks $(R R=1.40$, $\mathrm{p}=0.019$ ) were associated with an increase in injury. There was no association between workload ratio and injury in $\mathrm{U} 21$.

The significant link between high cumulated 3 -weeks and 4 weeks workloads and injury in U21 confirmed the requirement to monitor the internal subjective workload in U21 in order to prevent injury. Further studies exploring the relationships between workload and injury are required in football academy.

Keywords: Training, Academy, Team Sport, Injury prevention. 
26 Mean injury incidence (match and training) across seven UEFA clubs during seven

27 seasons was reported as eight injuries per 1,000 hours of exposure, which corresponds to 50 injuries per season in a team of 25 players, or two injuries per player per season (Ekstrand, Hagglund, \& Walden, 2011). This injury incidence is 1,000 times higher than in typical industrial occupations considered as highly risked (Drawer and Fuller, 2002).

During the 2012 Olympies, the football competition represented the highest level of injury, with 35.2\% of total number of injuries during the Olympies (Engebretsen et al.,

2013). This high injury incidence highlights the importance of injury prevention in elite 34 football.

According to the model of van Mechelen (1992) about the prevention of sports injuries, once the injury incidence and severity have been evaluated through epidemiological studies, the second step to prevent injury risk is to identify the risk factors and injury mechanisms. The third step is to introduce measures that are likely to reduce the future risk and/or severity of injuries. The last step is characterised by

41 assessing the effect of the measures by repeating the first step (Van Mechelen, Hlobil, \& Kemper, 1992). According to this model, several injury risk factors have been

43 identified. In a survey, McCall et al. (2014a) reported that elite football

44 medicine/science practitioners considered previous injury as the most important injury risk factor (121 points of importance on a score of 132). In their systematic review,

46 McCall et al. (2014b) confirmed the practitioners' perceptions: previous injury was the

47 injury risk factor with the highest level of scientific evidence (level $2++$ according to

48 the system for graded recommendations guidelines published in British Medical

49 Journal) (Harbour and Miller, 2001). A previous hamstring, calf, groin or knee injury 
increases two to three times the risk to sustain a new injury in the same body part during

51 the following season (Hagglund et al., 2013). A previous injury also increases the overall injury risk, and not only in the previously injured body part (hazard ratio $=2.7$, CI95\% 1.7 to 4.3) (Hagglund et al., 2006). As a previous injury is a non-modifiable internal injury risk factor, it is important to prevent initial injuries which occur during the youth academy period. The fact to have already been injured during this period would become a non-modifiable risk factor in their future professional career. Moreover, during an injury period, youth players do not have the same training protocol, it could represent an additional gap to bridge in their improvements. Several studies examined the injury incidence in elite youth football academy. In a systematic review of literature, Pfirrmann et al. (2016) reported, in youth academies, an overall injury incidence from 2.0 to 19.4 injuries per $1,000 \mathrm{~h}$ of exposition and a training injury incidence in youth academies from 3.7 to 11.4 injuries per $1,000 \mathrm{~h}$ of training. For the last year spent in the academy, the overall injury incidence of U18 and U19 (between 6.8 and 10 per 1,000h of exposition) (Nilsson et al., 2016 ; Renshaw \& Goodwin, 2016) is comparable to the one reported in elite professional football players ( 7.6 injuries per

66 1,000h of exposition) (Ekstrand, Hagglund, Kristenson, Magnusson \& Walden, 2013). These results concerning the high injury incidence in youth football academy highlights the needs to identify injury risk factors with this population in order to implement injury

69 prevention strategies, especially to reduce the risk to sustain a first injury. Although a 70 few studies have already dealt on the identification of the risk factors and injury 71 prevention in youth academy (Bowen et al., 2017), most of the studies dealt on high72 level professional players (Ekstrand, Hagglund, \& Walden, 2011; Hagglund, Walden, \& 73 Ekstrand, 2013). 
In their survey, McCall et al. (2014a) reported that the practitioners considered the fatigue (105 points of importance on a maximal score of 132) as the second most important injury risk with professional football players. Fatigue could come from the repetition of training and matches. Several studies found a significant association between workload and injury incidence among professional football players (Malone et al., 2017; Lu et al., 2017 ; Jaspers et al., 2017). Two reviews of literature concluded that internal/subjective tools were more sensitive and related to injury incidence than external and/or objective tools (Saw, Main, \& Gastin, 2016; Jones, Griffiths, \& Mellalieu, 2017). Jones, Griffiths, \& Mellalieu (2017) included 21 studies evaluating the association between internal workload and injury incidence in sports in a systematic review of literature.The majority $(90 \%)$ of these studies concerned team sports. The authors concluded that there was a moderate evidence that the internal workload was associated with injury incidence. In professional football, Malone et al. (2017) identified that an absolute workload calculated with sRPE higher than 1,500 arbitrary units (A.U.) was associated with an elevated injury risk, and that an acute:chronic workload ratio calculated with the sRPE between 1.00 and 1.25 was associated with a lower injury incidence in elite football players. In youth elite football players, one study identified an association between the one week absolute workload calculated using the session Rate of Perceived Exertion (sRPE), using a modified perception scale (Borg, CR-10) and the injury incidence (OR=1.01, 95\%CI 1.00 to 1.06) (Brink et al., 2010). However, in this study, the workload was calculated only for 1 week, while associations between external workload and injury incidence during 2, 3 or 4 cumulative weeks and A:C ratios have been identified (Bowen et al., 2017). To our knowledge, no study aimed at evaluating the association of absolute internal workload during several weeks, and acute:chronic internal workload ratio and injury in a elite football academy. Therefore, 
99 the aim of this study is to analyse the relationships between several combinations of

100 internal workload using the sRPE and the injury among football players in an elite

101 football academy.

102

$103 \quad$ Materials and Methods

$104 \quad$ Subjects

105 One hundred twenty-two elite young football players (height: $178.6 \pm 6.8 \mathrm{~cm}$; body

106 mass: $70.9 \pm 7.3 \mathrm{~kg})$ from $\mathrm{U} 19(\mathrm{n}=52$; age: $16.8 \pm 0.9)$ and $\mathrm{U} 21(\mathrm{n}=70$; age: $20.1 \pm 0.3)$

107 squads of a football academy in an elite football club playing in first French League and

108 taking part regularly in European competitions were followed during four and five

109 seasons respectively. All players from the U19 and the U21 squads were included in the

110 study. The players lived in the academy. If a player joined the team during the

111 observational period, he was included from the date he joined the team. A player who

112 left the team during the observational period was excluded from the study from the date

113 he left the team. If a player was already injured at the start of data collection, he was

114 included in the study but this injury was excluded (Fuller et al., 2006). All players were

115 informed and consented to take part in the study. This study was conducted in

116 accordance with the local ethical committee on biomedical research (CCTIRS\#10544)

117 and the standards of the declaration of Helsinki.

\section{Methodology}

120 This study was a prospective cohort study. An injury was defined, in accordance with

121 the FIFA consensus, as any physical complaint sustained by a player that resulted from

122 a football match or football training, that made the player unable to participate in future

123 football training or a match (Fuller et al., 2006). 
126 for its use with athletes and football players (Foster, 1998 ; Impellizzeri et al., 2004).

127 Players were instructed to rate the global intensity of all sessions and matches using a

128 modified category ratio scale going from 0 to 10 based on the scale developed by Borg

129 (1987) by answering the following question: 'How was your workout?'. The sRPE was

130 collected 30 minutes after completion of the session/match by a sport clinician working

131 in the club responsible for the collection of the data. The players were isolated to

132 answer in order not to be influenced by other players. Workload, expressed in arbitrary

133 units (AU) was calculated by multiplying the perceived intensity by the session or

134 match duration (Foster et al., 2001); all training sessions and all matches were included.

135 All the training sessions and matches were on natural grass. The workload was

136 calculated on a daily basis with the methods of rolling days blocks (everyday, a new

137 workload was calculated based on the preceding days) (Hulin et al., 2016; Bowen et al.,

138 2017). The absolute workload was the sum of the load for the last 7 days (one-week

139 workload), 14 days (2-weeks workload), 21 days (3-weeks workload) and 28 days (4-

140 weeks workload) were calculated. To determine A:C ratios, the one-week workload was

141 divided by the total workload of the last 28 days, divided by 4 for the 4 -weeks A:C ratio

142 (formula: one-week workload / (last 28 days workload/4)), the total load of the last 21

143 days divided by 3 for the 3-weeks A:C ratio (one-week workload / (last 21 days

144 workload/3)) and the total load of the last 14 days divided by 2 for the 2 weeks A:C

145 ratio (one-week workload / (last 14 days workload/2)) (Malone et al., 2017). The week-

146 to-week load changes were also calculated by dividing the 1-week load by the

147 accumulated load of the previous 7 days. The workload was known by the practitioners

148 who could use the data to regulate the workload. In U19, the group (and not individual) 
149 workload was regulated on a weekly basis by the practitioners. The workload was

150 analysed in the end of each week and the practitioners aim was to reach a weekly mean

151 of 2,500 A.U, because they considered it was the optimal workload to reduce the injury

152 risk while improving players fitness qualities. The data were not taken into account in

153 U21 to regulate the workload.

154

Statistical Analysis

156 A Poisson regression analysis was performed with IBM SPSS Statistics Version 20 for

157 the 1-week, 2-weeks, 3-weeks and 4-weeks absolute workload and the A:C workload

158 ratios to assess the link between these factors and injury incidence and calculate relative

159 risk (RR). The absolute workload and the A:C workload ratios were log-transformed

160 when the scores were not normally distributed.

161 The daily probability to sustain an injury was calculated by dividing the number of

162 injuries by the number of days of observation, multiplied by 100.

163

$164 \quad$ Results

165 A total of 122 players have been followed during the period of observation. The number

166 of players in each squad, season by season, are described in table 1. In U19 category, a

167 total 52 players were followed (24 players were followed during one season, 26 players

168 were followed during two seasons, 2 players were followed during 3 seasons). In U21

169 category, a total of 70 players were followed (41 players were followed during one

170 season, 16 players were followed during 2 seasons, 8 players were followed during 3

171 seasons, 4 players were followed during 4 seasons and one player was followed during

172 the 5 seasons of observation). It represents a total of 200 player-seasons, 17,778 days in

173 the U19 and of 26,672 days in the U21 were recorded. 
A total of 182 injuries were recorded in the U19 category (119 non-contact +63

contact injuries) and of 307 injuries (215 non-contact +92 contact injuries) were

recorded in the U21 category. It represents a global injury incidence of 7.6 injuries per

U21. The daily probability to sustain an injury was $1.02 \%$ in U19 and $1.15 \%$ in U21.

In U19, the mean weekly workload was $2046 \pm 705$ AU; the mean 2 weeks

workload was $3813 \pm 1291$ AU; the mean 3 weeks workload was $5501 \pm 1831$ AU and the mean 4 weeks absolute workload was $7104 \pm 2334$ AU. No link was found between absolute workload, cumulative absolute workload ( 2 weeks, 3 weeks, 4 weeks) and global, non-contact or contact injuries with U19 players. These results are described in table 2. No link was found between none of the A:C workload ratio and global, noncontact and contact injuries with U19 players, as described in table 3. workload was $3783 \pm 1211 \mathrm{AU}$; the mean 3 weeks workload was $5497 \pm 1740$ AU and the mean 4 weeks workload was $7145 \pm 2254$ AU. The results concerning the link between absolute workload and global, non-contact and contact injuries in U21 are described in

194 table 4. An association was found between the cumulative 3 weeks absolute workload 195 and injury incidence $(\mathrm{RR}=1.39, \mathrm{p}=0.026)$ and between the cumulative 4 weeks absolute workload and injury incidence $(\mathrm{RR}=1.40, \mathrm{p}=0.019)$. There was no association between

197 the A:C workload ratio and the injury incidence with U21 players. The results are 198 described in table 5. 


\section{Discussion}

204 The aim of this study was to analyse the relationship between workload and injury

205 incidence in elite football academy players. The main findings showed that there was no association between absolute or A:C workload ratio with U19 players, while there was an association between 3 weeks and 4 weeks cumulative absolute workload with U21 players.

In the current study, the overall injury incidence was 7.6 injuries per $1,000 \mathrm{~h}$ of 211 exposition with U19 and 9.6 injuries per 1,000h of exposition with U21 players. These

212 results confirm those of previous studies with an overall injury incidence between 6 and

21310 injuries per 1,000h of exposition with players in U18 and U19 categories (Nilsson et 214 al., 2016; Renshaw \& Goodwin, 2016). This injury incidence is also close to the injury 215 incidence of elite professional football teams ( 8 injuries per $1,000 \mathrm{~h}$ of exposition)

216 (Ekstrand, Hagglund, \& Walden, 2011). When transforming these results into daily 217 probability, the overall daily probability to sustain an injury in U19 is $1.02 \%$ per player 218 and in U21 is $1.15 \%$ per player. The daily probability to sustain an injury per player 219 highlights that even if the injury incidence is very high compared to other activities 220 (Ekstrand, 2013), the daily probability to sustain an injury in a youth academy is low, 221 being approximately $1 \%$. 
No link between absolute workload, A:C workload ratio and injury incidence was found for the U19. These results about the lack of significant relationship between absolute workload and the occurrence of injury are different of a previous study led by Brink et al. (2010), who found an association between internal workload calculated using the sRPE and the injury incidence. However, the methodology used are different. First of all, Brink et al. analysed the sum of the workload week after week, while in the current study, a rolling days method was used to analyse the workload day after day. This is a major difference between the two studies as an injury at the beginning of the week or in the end of the week could lead to big changes in the weekly workload with Brink et al.'s methodology (2010). In the study led by Brink et al. (2010), an odd ratio was calculated, while in the current study, a Poisson regression was used, providing a relative risk. The injury incidence in Brink et al. study (2010) (37.55 per 1,000h of match and 11.14 per $1,000 \mathrm{~h}$ of training) was higher than the one in the present study (7.6 in U19 and 9.6 in U21). The probability to find a significant association between a potential risk factor and an event depends on the event frequency. It means that the higher the injury incidence is, the higher the probability to find a significant statistical association is (Bahr and Holme, 2003). The method to calculate the workload was not exactly the same as the authors used a 15-point scale to rate the perceived intensity and multiply the perceived exertion by the number of hours of practice while a 10-point

242 scale was used in the present study and the exertion was multiplied by the number of

243 minutes of practice. It is therefore difficult to compare the workload data range width

244 while the data range width of the independent factor modifies the results of a regression 245 (Salgueiro da Silva and Seixas, 2017). Another difference in the results could be explained by a different definition of injury, as Brinks et al. (2010), defined the injury

247 as any physical complaint sustained by a player that results from a soccer match or 
soccer training and leading to time loss or medical attention. In the present study, only

249 the complaint leading to time loss were taken into account. Given the very low odd ratio

$250(\mathrm{OR}=1.01,95 \%$ CI 1.00 to 1.02$)$ reported by Brink et al. (2010), these changes in the

251 methodology could explain the absence of association in the current study and the

252 differences between the two studies.

In the $\mathrm{U} 21$, no association was found between none of the A:C workload while an association was found between the cumulative absolute 3 weeks and 4 weeks workload and the injury incidence. In the current study, no association has been found with none of the workload calculated over the last 7 days (absolute 1 week workload or A:C workload ratio). These results does not allow to identify a link between the internal A:C workload ratios calculated with sRPE and injury incidence with academy players while this association has been identified with professional players (Malone et al., 2017). In professional football, an A:C ratio between 1.00 and 1.25 has been identified as an injury protective factor (Malone et al., 2017). An elevated A:C workload ratio is

263 the result of the combination of a low chronic workload and a high acute workload

264 (Blanch \& Gabbett, 2016). It means that a low chronic workload or spikes in the workload calculated with sRPE should be avoided in elite level football players in order to reduce the injury incidence (Blanch \& Gabbett, 2016). Jaspers et al. (2018) identified that an elevated workload calculated with the help of sRPE during two weeks was associated with an elevated incidence of overuse injury with elite football players while a medium workload during four weeks was associated with a decrease in injury incidence in comparison with a low workload calculated with sRPE. This result

271 indicates that a minimum level workload should be necessary to avoid an increase in

272 injury risk, and that a chronic workload too low could be an injury risk factor among 
273 professional football players. These results highlight the association between injury

274 incidence and acute and chronic workload calculated with sRPE in professional

275 football. This association has not been found in the present study with academy players.

276 Differences between players playing in a youth football academy and professional

277 football players playing in European competitions could be explained by differences in

278 the changes in acute workload. Large changes in workload sustained by professional

279 football players could occur during the congested schedule with two to three-games per

280 week. The schedule in youth category seems to be more regular without congested

281 periods, leading to smaller changes in the acute workload. These differences in the

282 competitions schedules could explain the absence of association between A:C workload

283 ratio and injury incidence in the U19 and U21 age categories.

The difference in results between U19 and U21 in the present study could be explained in part by the smaller number of injuries recorded in U19 compared to U21 (182 vs 307), which is explained by a lower incidence (7.6 vs 9.6) and shorter period of observation in U19 in comparison with the U21 (4 seasons vs 5 seasons). There was a similar proportion of non-contact injuries between U19 and U21 (65\% in U19 vs $71 \%$ in U21), but a lower number of non-contact injuries recorded in U19 (119 vs 215),

291 which also could explain the absence of association in U19 as non-contact injuries are considered easier to prevent than contact injuries (Gabbett et al., 2010). As explained in

293 the introduction, a previous injury is the strongest injury risk factor. In future studies, it

294 may be interesting to evaluate the effect of a previous injury on the ability of a player to 295 sustain high workload, as the present results indicate that older players (U21) are more 296 sensitive to high workload, which may be linked to a higher proportion of previously 297 injured players with older players. 
This study presents some limitations. First of all, the current study identified an association between absolute workload and injury incidence with players in a football academy but it does not necessarily mean that there is a causal connection between workload and injury incidence (Bahr, 2016). Although very complicated to implement

303 in the real high-level sport world, other studies and randomised controlled trials should

304 be assessed to analyse the effect of a controlled workload on the injury incidence, in an isolated way, to confirm a causal connection (Bahr, 2016). As a cohort study, the design represents a limit. The observation of the players means that the results are influenced by players sustaining several injuries and as such are considered as repeated

308 independent observations while these injuries are multifactorial and are linked to a lot of

309 factors dependent of the player observed, as, for example, the ability to cope with very

310 high load and/or to large variations in workload. One of the limits of this study is the

311 low injury incidence in this study with only 182 injuries for 17,778 days of observation

312 in U19 and 372 injuries for 26,672 days of observation in U21, representing a daily

313 probability to sustain an injury of $1.02 \%$ in U19 and of $1.15 \%$ in U21. This low

314 probability could explain in part the absence of statistical association in U19 as a low

315 occurrence of an event reduces the probability to find an association between this event

316 and an independent factor (Bahr and Holme, 2003). Another limit of the study concerns

317 the practitioners who recorded the data. If they adapted the workload according to the

318 data recorded to protect some players with very high of low workloads, it would impact

319 the results. This limit could also partly explain the absence of results in U19 compared

320 to the results in U21. In U19, the workload was regulated on a weekly basis by the

321 practitioners. The objective for the practitioners in U19 was to reach a mean weekly

322 group workload of 2,500 A.U., and was analysed in the end of each week to decide how 
to manage the group workload in the following week. It could explain why the

324 workload is not associated with the injury incidence in U19. In U21, the data were known by the practitioners but not used to regulate the workload, which could partly explain the differences in the results between the two categories.

Despite these limits, this study presents some interesting strengths. First of all, to our knowledge, this is the first study with elite football academy players analyzing the associations of multiple combinations of internal absolute workload and workload ratios with injury incidence.

With 122 players followed and 200 player-seasons, the cohort of this study was

334 large compared to other studies in the same topic. It is, to our knowledge, the first longitudinal study concerning young football players led during a period as long as five full seasons. The players followed were football players from an elite football academy.

It means that there was a very good control about the workload with no missing data and a very good control of the outside activities of the players as most of the players were staying in the academy. It gives a very high level of confidence to the recorded workload.

\section{Conclusion}

343 In conclusion, the results of this study indicated that the internal workload calculated

344 using the sRPE was not associated with injury incidence in U19. In the U21 category,

345 the absolute workload cumulated during 21 or 28 days is positively associated with the

346 injury incidence. This result indicates that practitioners working with young football

347 players could calculate the internal workload and use the sRPE during their late years of 
academy in order to potentially reduce the injury incidence. Further studies are required

349 in these age categories to analyse these associations.

350

\section{Acknowledgements}

352 The authors thank all the players who took part in the study.

353

354

\section{Declaration of interest statement}

355

The authors report no conflict of interest.

356

357

Akenhead, R., \& Nassis, G. P. (2016). Training load and player monitoring in highlevel football: current practice and perceptions. International Journal of Sports

361

362

Bahr R., \& Holme I. (2003). Risk factors for sports injuries - a methodological approach. British Journal of Sports Medicine, 37, 384-392. Physiology and Performance, 11, 587-793.

Blanch, P., \& Gabbett, T. J. (2016). Has the athlete trained enough to return to play

Bahr, R. (2016). Why screening tests to predict injury do not work and probably never will...: a critical review. British Journal of Sports Medicine, 50, 776-780.

Borg, G., Hassmen, P., \& Lagerstrom, M. (1987). Perceived exertion related to heart rate and blood lactate during arm and leg exercise. European Journal of Applied Physiology and Occupational Physiology, 56, 670-685. 
Bowen, L., Gross, A. S., Gimpel, M., \& Li, F. X. (2017). Accumulated workloads and the acute:chronic workload ratio relate to injury risk in elite youth football players. British Journal of Sports Medicine, 51, 452-459.

Brink, M. S., Visscher, C., Arends, S., Zwerver J., Post W. J., \& Lemmink K. A. P. M. (2010). Monitoring stress and recovery: new insights for the prevention of injuries and illnesses in elite youth soccer players. British Journal of Sports Medicine, 44, 809-815.

Carey, D. L., Blanch, P., Ong, K. L., Crossley, K. M., Crow, J., \& Morris, M. E. (2016). Training loads and injury risk in Australian football-differing acute:chronic workload ratios influence match injury risk. British Journal of Sports Medicine, $51,1215-1220$

Ekstrand J., Hagglund M., \& Walden M. (2011). Epidemiology of muscle injuries in professional football (soccer). American Journal of Sports Medicine, 39, 12261232.

Ekstrand, J., Hagglund, M., \& Walden, M. (2011). Injury incidence and injury patterns in professional football: the UEFA injury study. British Journal of Sports Medicine, 45, 553-558.

Ekstrand, J. (2013). Keeping your top players on the pitch: the key to football medicine at the professional level. British Journal of Sports Medicine, 47, 723-724.

Foster, C. (1998). Monitoring training in athletes with reference to overtraining syndrome. Medicine \& Science in Sports \& Exercise, 30, 1164-1168.

Foster, C., Florhaud, J. A., Franklin, J., Gottschall, L., Hrovantin, L. A., Parker, S., Doleshal, P., \& Dodge, C. (2001). A new approach to monitoring exercise training. Journal of Strength and Conditioning Research, 15, 109-115.

Fuller, C. W., Ekstrand, J., Junge, A., Andersen, T. E., Bahr, R., Dvorak, J., Hägglund, M., McCrory, P., \& Meeuwisse, W. H. (2006). Consensus statement on injury 

definitions and data collection procedures in studies of football (soccer) injuries. British Journal of Sports Medicine, 40, 193-201.

Gabbett, T. J. (2010). The development and application of an injury prediction model for noncontact, soft-tissue injury in elite collision sport athletes. Journal of Strength and Conditioning Research, 24, 2593-2603.

Hagglund, M., Walden, M., \& Ekstrand, J. (2006). Previous injury as a risk factor for injury in elite football: a prospective study over two consecutive seasons. British Journal of Sports Medicine, 40, 767-772.

Hagglund, M., Walden, M., \& Ekstrand, J. (2013). Risk factors for lower extremity muscle injury in professional soccer. American Journal of Sports Medicine, 41, 327-335.

Harbour, R., \& Miller, J. (2001). A new system for grading recommendations in evidence based guidelines. British Medical Journal, 323, 334-336.

Hulin, B. T., Gabbett, T. J., Lawson D. W., Caputi P., \& Sampson J. A. (2016). The acute:chronic workload ratio predicts injury: high chronic workload may decrease injury risk in elite rugby players. British Journal of Sports Medicine, 50, 231-236.

Impellizzeri, F. M., Rampinini, E., Coutts, A. J., Sassi, A., \& Marcora, S. M. (2004). Use of RPE-based training load in soccer. Medicine \& Science in Sports \& Exercise, 36, 1042-1047.

Jaspers, A., Brink M. S., Probst, S. G., Frenken W. G., \& Helsen W. F. (2017). Relationships between training load indicators and training outcomes in professional soccer. Sports Medicine, 47, 533-544.

Jaspers, A., Kuyvenhoven, J. P., Staes, F., Frencken, W. G. P., Helsen, W. F., \& Brink, M. S. (2018). Examination of the external and internal load indicators 
association with overuse injuries in professional soccer players. Journal of Science and Medicine in Sport, 21, 579-585

Jones, C. M., Griffiths, P. C., \& Mellalieu, S. D. (2017). Training load and fatigue marker associations with injury and illness: A systematic review of longitudinal studies. Sports Medicine, 47, 943-974.

Lu, D., Howle, K., Waterson, A., Duncan, C., \& Duffield, R. (2017). Workload profiles prior to injury in professional soccer players. Science and Medicine in Football, 3, 237-243.

Malone, S., Owen, A., Newton, M., Mendes, B., Collins, K. D., \& Gabbett, T. J. (2017). The acute:chronic workload ratio in relation to injury risk in professional soccer. Journal of Science and Medicine in Sport, 20, 561-565.

McCall, A., Carling, C., Nedelec, M., Davison, M., Le Gall, F., Berthoin, S., \& Dupont, G. (2014a). Risk factors, testing and preventative strategies for non-contact injuries in professional football: current perceptions and practices of 44 teams from various premier leagues. British Journal of Sports Medicine, 49, 583-589.

McCall, A., Carling, C., Michael, D., Nedelec, M., Le Gall, F., Berthoin, S., \& Dupont, G. (2014b). Injury risk factors, screening tests and preventative strategies: a systematic review of the evidence that underpins the perceptions and practices of 44 football (soccer) teams from various premier leagues. British Journal of Sports Medicine, 49, 583-589.

Nilsson, T., Ostenberg, A. H., \& Alricsson, M. (2016). Injury profile among elite male youth soccer players in a Swedish first league. Journal of Exercise Rehabillitation, 12, 83-89.

Pfirrmann, D., Herbst, M., Ingelfinger, P., Perikles, S., \& Tug, S. (2016). Analysis of injury incidences in male professional adult and elite youth soccer players: A systematic review. Journal of Athletic Training, 51, 410-424. 
Renshaw, A., \& Goodwin P. C. (2016). Injury incidence in a Premier League youth soccer academy using the consensus statement: a prospective cohort study.

481

Salgueiro da Silva, M. A., \& Seixas, T. M. (2017). The role of data range in linear regression. The Physics Teacher, 55, 371-372.

484

485

Saw, A. E., Main, L. C., \& Gastin, P. B. (2016). Monitoring the athlete training response: subjective self-reported measures trump commonly used objective

488

van Mechelen, M., Hlobil, H., \& Kemper, H. C. (1992). Incidence, severity, aetiology and prevention of sports injuries. A review of concepts. Sports Medicine, 14, 82-

492

Walden M., Hagglund M., \& Ekstrand J. (2005) UEFA Champions League study: a 494 prospective study on injuries in professional football during the 2001-2002 season. British Journal of Sports Medicine, 39, 542-546.

496

497 
Table 1: Number of players observed in U19 and U21 during the 5 seasons of observation.

\begin{tabular}{lcc}
\hline & $\begin{array}{c}\text { Number of players observed } \\
\text { in U19 }\end{array}$ & $\begin{array}{c}\text { Number of players observed } \\
\text { in U21 }\end{array}$ \\
\hline $\mathbf{2 0 1 2 - 2 0 1 3}$ & $\mathrm{X}$ & 21 \\
$\mathbf{2 0 1 3 - 2 0 1 4}$ & 18 & 26 \\
$\mathbf{2 0 1 4 - 2 0 1 5}$ & 16 & 24 \\
$\mathbf{2 0 1 5 - 2 0 1 6}$ & 23 & 28 \\
$\mathbf{2 0 1 6 - 2 0 1 7}$ & 25 & 19 \\
\hline
\end{tabular}

500

501 Table 2: Relative risk RR (95\% confidence interval) and p-value for an increase in

502 cumulative workload for the last 7 days (1 week), 14 days (2 weeks), 21 days ( 3 weeks)

503 and 28 days (4weeks) in the U19 age category.

\begin{tabular}{lcc}
\hline & $\begin{array}{c}\text { RR } \\
(\mathbf{9 5 \%} \mathbf{C I})\end{array}$ & $\mathbf{p}$ \\
\hline $\mathbf{1}$ week workload & 1.11 & 0.44 \\
$\mathbf{2}$ weeks cumulative workload & $(0.84-1.50)$ & 0.85 \\
$\mathbf{3}$ weeks cumulative workload & 1.03 & 0.82 \\
$\mathbf{4}$ weeks cumulative workload & $(0.77-1.38)$ & 0.97 \\
\hline
\end{tabular}

504

505 Table 3: Relative risk RR (95\% confidence interval) and p-value for an increase in

506 Acute:Chronic workload with a chronic workload calculated over the last the last 28

507 days (4weeks), the last 21 days (3 weeks), the last 14 days ( 2 weeks) and the week to

508 week changes in workload in the U19 age category.

\begin{tabular}{lcc}
\hline & $\begin{array}{c}\text { RR } \\
(\mathbf{9 5 \%} \mathbf{C I})\end{array}$ & $\mathbf{p}$ \\
\hline $\mathbf{4}$ weeks A:C workload & 1.01 & 0.73 \\
$\mathbf{3}$ weeks A:C workload & $(0.96-1.07)$ & 0.91 \\
$\mathbf{2}$ weeks A:C workload & 1.00 & 0.82 \\
$\begin{array}{l}\text { Week to week workload } \\
\text { changes }\end{array}$ & $(0.95-1.06)$ & 0.93 \\
\hline
\end{tabular}


510 Table 4: Relative risk RR (95\% confidence interval) and p-value for an increase in

511 cumulative workload for the last 7 days (1 week), 14 days ( 2 weeks), 21 days (3 weeks)

512 and 28 days (4weeks) in the U21 age category.

\begin{tabular}{lcc}
\hline & $\begin{array}{c}\mathbf{R R} \\
(\mathbf{9 5 \%} \mathbf{C I})\end{array}$ & $\mathbf{p}$ \\
\hline $\mathbf{1}$ week workload & 1.18 & 0.19 \\
$\mathbf{2}$ weeks cumulative workload & $(0.92$ to 1.52$)$ & 0.076 \\
$\mathbf{3}$ weeks cumulative workload & 1.28 & 0.026 \\
$\mathbf{4}$ weeks cumulative workload & $(0.97$ to 1.69$)$ & 0.019 \\
\hline
\end{tabular}

513

514 Table 5: Relative risk RR (95\% confidence interval) and p-value for an increase in

515 Acute:Chronic workload with a chronic workload calculated over the last the last 28

516 days (4weeks), the last 21 days (3 weeks), the last 14 days (2 weeks) and the week to

517 week changes in workload in the U21 age category.

\begin{tabular}{lcc}
\hline & $\begin{array}{c}\text { RR } \\
(\mathbf{9 5 \%} \mathbf{C I})\end{array}$ & $\mathbf{p}$ \\
\hline $\mathbf{4}$ weeks A:C workload & 0.89 & 0.34 \\
$\mathbf{3}$ weeks A:C workload & $(0.71$ to 1.13$)$ & 0.37 \\
$\mathbf{2}$ weeks A:C workload & 0.88 & 0.47 \\
& $(9.66$ to 1.16$)$ & 0.91 \\
\hline $\begin{array}{l}\text { Week to week workload } \\
\text { changes }\end{array}$ & 0.86 & \\
\hline
\end{tabular}

518 